\title{
Aging, Osteocytes, and Mechanotransduction
}

\author{
Haniyeh Hemmatian $^{1,2}$ • Astrid D. Bakker ${ }^{2}$. Jenneke Klein-Nulend ${ }^{2}$. \\ G. Harry van Lenthe ${ }^{1}$
}

Published online: 11 September 2017

(C) The Author(s) 2017. This article is an open access publication

\begin{abstract}
Purpose of Review The bone is able to adapt its structure to mechanical signals via the bone remodeling process governed by mechanosensitive osteocytes. With aging, an imbalance in bone remodeling results in osteoporosis. In this review, we hypothesized that changes in lacunar morphology underlie the decreased bone mechanoresponsiveness to mechanical loading with aging.

Recent Findings Several studies have reported considerable variations in the shape of osteocytes and their lacunae with aging. Since osteocytes can sense matrix strain directly via their cell bodies, the variations in osteocyte morphology may cause changes in osteocyte mechanosensitivity. As a consequence, the load-adaptive response of osteocytes may change with aging, even when mechanical loading would remain unchanged.

Summary Though extensive quantitative data is lacking, evidence exists that the osteocyte lacunae are becoming smaller and more spherical with aging. Future dedicated studies might reveal whether these changes would affect osteocyte mechanosensation and the subsequent biological response,
\end{abstract}

This article is part of the Topical Collection on Osteocytes

Jenneke Klein-Nulend

j.kleinnulend@acta.nl

G. Harry van Lenthe

harry.vanlenthe@kuleuven.be

1 Biomechanics Section, Department of Mechanical Engineering, KU Leuven, Celestijnenlaan 300c, 3001 Leuven, Belgium

2 Department of Oral Cell Biology, Academic Centre for Dentistry Amsterdam (ACTA), University of Amsterdam and Vrije Universiteit Amsterdam, Amsterdam Movement Sciences, Amsterdam, The Netherlands and whether this is (one of) the pathways involved in agerelated bone loss.

Keywords Osteocyte lacuna $\cdot$ Aging ·

Mechanotransduction $\cdot$ Bone mechanobiological response

\section{Introduction}

Osteoporosis is a prevailing skeletal disease of aging [1 $\bullet \bullet]$. It is defined by low bone mass and associated with deterioration of the bone microarchitecture, leading to reduced bone strength and increased risk of fragility fractures. Osteoporosis is an economic as well as health burden resulting in 8.9 million osteoporotic fractures worldwide annually [2]. Hence, there is a strong socio-economic need to reduce the number of fractures. A better understanding of the biological mechanisms underlying bone loss with aging is crucial to reach this objective.

The skeleton is a dynamic organ with the capacity to adapt itself to its mechanical environment [3]. Bone adaptation to mechanical loading typically results in the formation of a bone structure that provides an appropriate resistance to fractures while using a small amount of material. The process of bone adaptation is controlled by mechanosensitive osteocytes. Osteocytes sense mechanical signals placed upon the bone, and consequently orchestrate the activity and recruitment of osteoblasts and/or osteoclasts by producing a multitude of signaling molecules (for extensive reviews, see KleinNulend et al., $2013[4 \bullet \bullet, 5 \bullet \cdot])$. Bone mass is determined by the overall metabolic action of the osteoblasts and osteoclasts, while local bone architecture results from local osteoblast and/ or osteoclast recruitment by osteocytes $[1 \bullet \bullet]$.

Age-related fragility fractures could reflect a deficit in bone mass and/or structural integrity, the main determinants of bone strength. A deficit in bone mass results in part from sex 
hormone insufficiency, in particular, reduced estrogen levels in postmenopausal women, leading to an overall negative balance between bone resorption and formation rate. An impaired bone architecture may result from a reduced osteocyte ability to control local osteoblast and/or osteoclast recruitment. Indeed, there is ample evidence linking diminished osteocyte sensitivity to age-related bone loss $[6,7]$. Thus, the combination of estrogen deficiency and impaired mechanosensitivity of osteocytes might create a major risk for osteoporotic bone fractures $[1 \bullet \cdot]$.

The ability of osteocytes to sense and respond to mechanical stimuli depends on many factors, such as the shape of the osteocyte cell bodies, number and length of the cell processes, structure of the cytoskeleton, and presence of primary cilia. One intriguing factor is osteocyte lacunar shape, which has been hypothesized to affect the transduction of strain on the whole bone to the direct osteocyte microenvironment [8]. It has been shown that considerable variations in the shape of osteocytes and their lacunae exist and that these variations may depend on anatomical location and the age of the bone $[9 \bullet, 10 \bullet, 11 \bullet \cdot$. Considering that a proper response of osteocytes to mechanical stimuli is highly important to maintain bone strength, we will address in this review the potential changes in osteocyte mechanosensivity with aging, and answer the question whether changes in lacunar morphology could underlie the alterations in the bone adaptive response seen with aging. We will also discuss novel methods for three-dimensional (3D) visualization and quantification of the lacunar network. In this review, we consider aging the cause of alterations in bone structure at both the micro and macrolevel. Furthermore, we consider osteocytes as mechanosensors that can modify their microenvironment, thereby affecting their mechanosensation and subsequent bone mechanobiological response.

\section{The Role of Osteocytes in Bone Turnover}

The osteocytes are considered to be the cells responsible for sensing mechanical signals on the bones and consequently orchestrating the activity of osteoblasts and osteoclasts (reviewed in Klein-Nulend et al., 2012 [5••]). The osteocyte cell bodies are embedded within the calcified bone matrix and reside in small cavities named lacunae. The cell bodies are interconnected through long dendritic cell extensions (50-60 per cell) which reside in small canals named canaliculi. The lacunae together with the canaliculi form the lacuno-canalicular network (LCN). The large surface area of osteocytes and their long processes allow fast transduction of signals.

The osteocytes are highly mechanosensitive cells and capable of directly influencing the bone-resorbing osteoclasts as well as the bone-forming osteoblasts. Mechanical stimulation of the osteocytes causes changes in their metabolic activity, i.e., they start to produce signaling molecules like Wnts, bone morphogenetic proteins (BMPs), nitric oxide (NO), and prostaglandin E2 (PGE2), thereby adjusting the differentiation, recruitment, and action of osteoblasts and osteoclasts, clearly pointing towards a mechanosensory function of the osteocytes [12-14]. Furthermore, there is substantial evidence that osteocytes are capable of changing their enzyme activity and RNA synthesis in the intact bone quickly after mechanical loading [15-17]. Ablating $80 \%$ of the osteocytes prevents the bone loss typically seen after unloading [18]. Thus, osteocytes seem to act as crucial regulators of osteoclastic resorption of the bone $[13,18,19]$. The production of RANKL by osteocytes regulates bone resorption, indicating the essential role of osteocytes in steering osteoclast activity [20,21].

The mechanisms by which osteocytes sense the mechanical loading, and which mechanical signal is actually being sensed, are poorly understood. The cytoskeleton likely plays a key role. It consists of a composite gel-like material of actin, microtubules, intermediate filaments, and their cross-linkers, and forms the scaffold determining cellular shape and stiffness [22]. Integrins anchor to the extracellular matrix and mechanically link the cell exterior to the cytoskeleton, forming transmembrane complex structures. These complexes are often clustered in focal adhesions, and likely function as mechanotransducers [23, 24]. The importance of anchoring mechanotransduction complexes that connect the extracellular matrix to the cytoskeleton predicts that the osteocyte cytoskeleton plays a key role in osteocyte mechanotransduction (reviewed in Klein-Nulend et al., 2012 [5••]). The cytoskeleton also determines the material and mechanical properties of the cells (resistance to shear or compression), enables cell migration, and is important for the transduction of intracellular molecules [5••].

There are several potential ways for osteocytes to sense mechanical loading $[4 \bullet \bullet, 5 \bullet \cdot$. First, bone matrix deformations resulting from mechanical loads placed on the bone cause interstitial fluid flow through the canaliculi along the osteocyte cell processes. Evidence for the occurrence of fluid flow in the bone has been provided by a study in mouse tibia [25]. The interstitial fluid flow "amplifies" tissue-level strains and gives rise to the secretion of signals by the osteocytes, which modulate the activity of osteoblasts and osteoclasts, resulting in an adaptive response to mechanical loading [25-29]. Second, the hydraulic pressure induced by loading could be another mechanism to activate osteocytes. It has been shown that a cyclic hydraulic pressure of $68 \mathrm{kPa}$ results in the production of signaling molecules in murine MLO-Y4 osteocytelike cells, and a pressure as low as $13 \mathrm{kPa}$ induces prostaglandin production by primary osteocytes in chicken calvariae [28, 30]. A third mechanism for sensing mechanical loading may be a direct response to matrix strains [31]. A substrate strain of 3400 microstrain is sufficient to increase the production of signaling molecule by osteoblasts [32]. Since osteocytes are more mechanosensitive than osteoblasts [28], one may expect 
that osteocytes would respond to lower strain levels. The inhomogeneities in the bone microstructure due to the osteocyte lacunar network can locally amplify the matrix strain to a magnitude that is sufficient to directly activate the osteocyte cell bodies [31].

From a mechanical point of view, it is to be expected that the three strain-sensation mechanisms are affected by lacunar shape, because this would affect the (shear) stresses applied to osteocytes, and lacunar shape could affect the strain amplification around the cell body. Furthermore, the magnitude of the osteocyte signal is likely related to the number of osteocytes contributing to the signal, hence, would be related to the number of lacunae. In order to elaborate these effects, an accurate quantification of the osteocytes and the LCN is essential. In the following sections, we will summarize different imaging techniques of the LCN.

\section{Visualization of Osteocyte Lacunar Network}

Direct quantitative analyses of osteocytes are extremely challenging, because preservation and 3D-visualization of osteocytes are difficult. In addition, the osteocytes are embedded in a stiff and strong bone, complicating the analyses further. Therefore, the osteocyte lacuna is often used as a proxy. Several techniques have been introduced to visualize and quantify osteocyte lacunar network including histological methods, light microscopy (LM), confocal laser scanning microscopy (CLSM), scanning electron microscopy (SEM), transmission electron microscopy (TEM), desktop microcomputed tomography, and synchrotron radiationbased CT (SR CT). Other techniques that are less commonly used are ptychographic X-ray CT, transmission X-ray microscopy (TXM) CT, serial-focused ion beam SEM (serial FIB SEM), and serial block-face SEM (SBF SEM). Different imaging techniques of the osteocyte lacunar network have been reviewed [33•, 34, 35, 36••, 37]. Table 1 briefly summarizes the pros and cons of the imaging methods of the osteocyte lacunar network.

Historically, histology was the method of choice to evaluate porosity. Although quantitative two-dimensional (2D)-histological and microscopic imaging techniques provide unique data on bone tissue dynamics, they cannot provide a complete visualization of bone microstructure as they are based on a limited number of 2D-sections. Additionally, 2D-methods typically overestimate bone microarchitecture because of preparation artifacts, and they are destructive in nature [69, 70]. These limitations might lead to misinterpretation. Therefore, a reliable and nondestructive method that allows to image at submicron resolution with a large field of view for a precise and accurate visualization and quantification and that avoids misinterpretation is needed. CT-based techniques are nondestructive and represent a 3D-methodology for

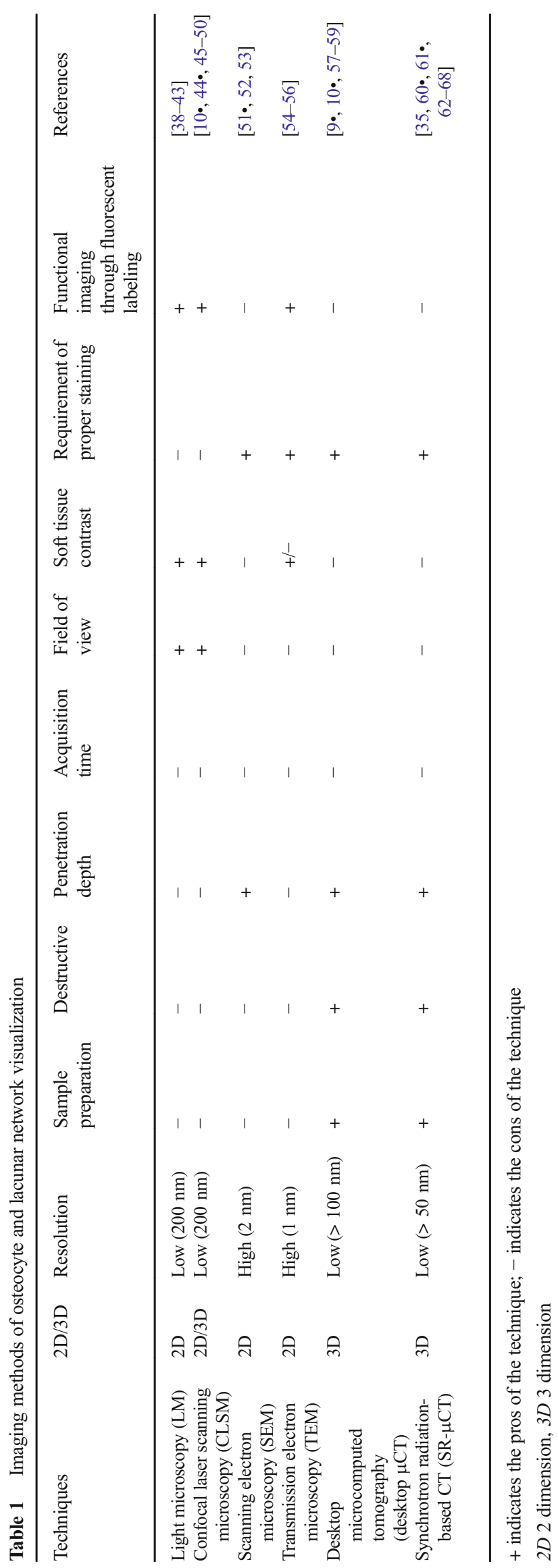


characterization of biological tissues. The main advantage of 3D-imaging technique-based CT is that they provide nondestructive quantitative data without preparation of the sample. Afterwards, the sample can still be processed for (dynamic) histomorphometry or immunohistochemistry. Recently, we showed that desktop microCT allows an accurate and precise visualization and quantification of the osteocyte lacunar network in the bone [57].

A direct measurement of the 3D stresses and strains acting on the osteocytes is extremely challenging, if not impossible [71]. As an alternative, most efforts have tried to quantify these using computational models. Computational models have been based on the idealized LCN geometries, yet it has been shown that idealized models are not appropriate to evaluate lacunar strains [72]. Indeed, recent developments in finite element (FE) modeling of the LCN based on confocal laser scanning microscopy have demonstrated huge variations between the results obtained from idealized and more realistic models [73, 74]. Hence, an accurate quantification of the lacunar network is essential. Based on accurate and highlydetailed computational models representing the osteocyte lacunar network, fluid shear stresses at the cell level can be calculated using computational fluid dynamic (CFD) [75•, 76] and finite element (FE) models [71, 72]. The development in 3D-visualization of the osteocyte LCN allows FE analysis based on realistic models of osteocytes and their canalicular network $[77,78,79]$.

\section{Osteocytes Modify Their Microenvironment, Leading to Alterations in Mechanotransduction}

As argued in the previous paragraphs, morphological alterations in the LCN are likely to affect the ability of osteocytes to sense and respond to mechanical stimuli. Osteocytes do not undergo these modifications passively, but they are actively involved in shaping their microenvironment and play a key role in maintaining bone mineral homeostasis. Indeed, given the high number of osteocytes and the extent of the LCN [80], small changes in the dimensions of the LCN would effectively lead to alterations in mechanotransduction. Osteocytes can enlarge their lacunar volume by removing the bone from their perilacunar bone matrix in a process called osteocytic osteolysis or perilacunar remodeling. Conversely, they can promote perilacunar bone formation, thereby reducing the lacunar volume [81, 82•, 83, 84]. Probably, the best evidence for osteocytic osteolysis and perilacunar bone formation is that during lactation in mice, the volume of osteocyte lacunae is larger than the osteocyte lacunar volume in virgin and postweaned animals in both the cortical and trabecular bone [82•]. Furthermore, continuous administration of parathyroid hormone can cause osteocytic osteolysis in the cortex of rat tibia [84].
Modifications in the morphology and orientation of osteocytes and their lacunae could result from hormonal changes, as well as from changes in mechanical loading. The alignment and shape of the osteocytes and their lacunae have been shown to be related to the direction of the mechanical loading $[10 \bullet, 85]$. Vatsa et al. [10•] found more flattened and elongated osteocytes and lacunae in fibula loaded unidirectionally than in the calvarial bone, which is loaded in different directions. Sugawara et al. [85] demonstrated irregularly shaped osteocytes distributed in different directions in the femur of embryonic mice in the absence of mechanical loading, whereas the osteocytes in the femur of 6-week-old mice subjected to mechanical loading were more flat and spindle-shaped, and orientated parallel to the longitudinal axis of the bone. Furthermore, in neurectomized mice under little or no mechanical loading during growth, the osteocytes were round without any preferred orientation. The actin filaments in the osteocyte cytoskeleton distribute in the same direction as the mechanical loading [86]. Besides, the osteocyte morphology might vary in bone pathologies, i.e., the shape of osteocytes and their lacunae are significantly different in the tibia of individuals with osteoporosis, osteopenia, and osteoarthritis [9•]. Osteocyte lacunae in the bone from osteopenic persons are large and round, lacunae from osteopetrotic persons are small and discoid shaped, whereas lacunae from osteoarthritic persons are large and elongated [9•]. Furthermore, in the osteopetrotic bone, the osteocyte lacunae are less orientated to the loading direction in comparison with the orientation of osteocyte lacunae in the osteoarthritic and osteopenic bone [9॰]. The variation in the shape and the alignment of osteocytes and their lacunae in different bone pathologies could reflect an adaptation to the different micromechanical environment with different matrix strain associated with differences in bone mineral density; however, conclusions about causal relations cannot be drawn based on observational data.

\section{Age-Related Changes in Bone Macro, Micro, and Nanostructure}

With advancing age, a negative balance in bone remodeling results in decreased bone mass and alterations in the bone structure at the macroscale, microscale, and nanoscale, which may be associated with decreased bone mechanical properties $[44 \cdot, 87 \bullet, 88]$, eventually leading to increased fracture risk with aging. In this section, we will report the aging-related changes in the bone architecture at different length scales, discuss the alterations in the mechanical properties as a consequence of bone structural changes, and evaluate the potential role of the osteocytes.

Aging is associated with changes in the geometrical macrostructure of both the trabecular and cortical bone. In the trabecular bone, aging is associated with a reduction in 


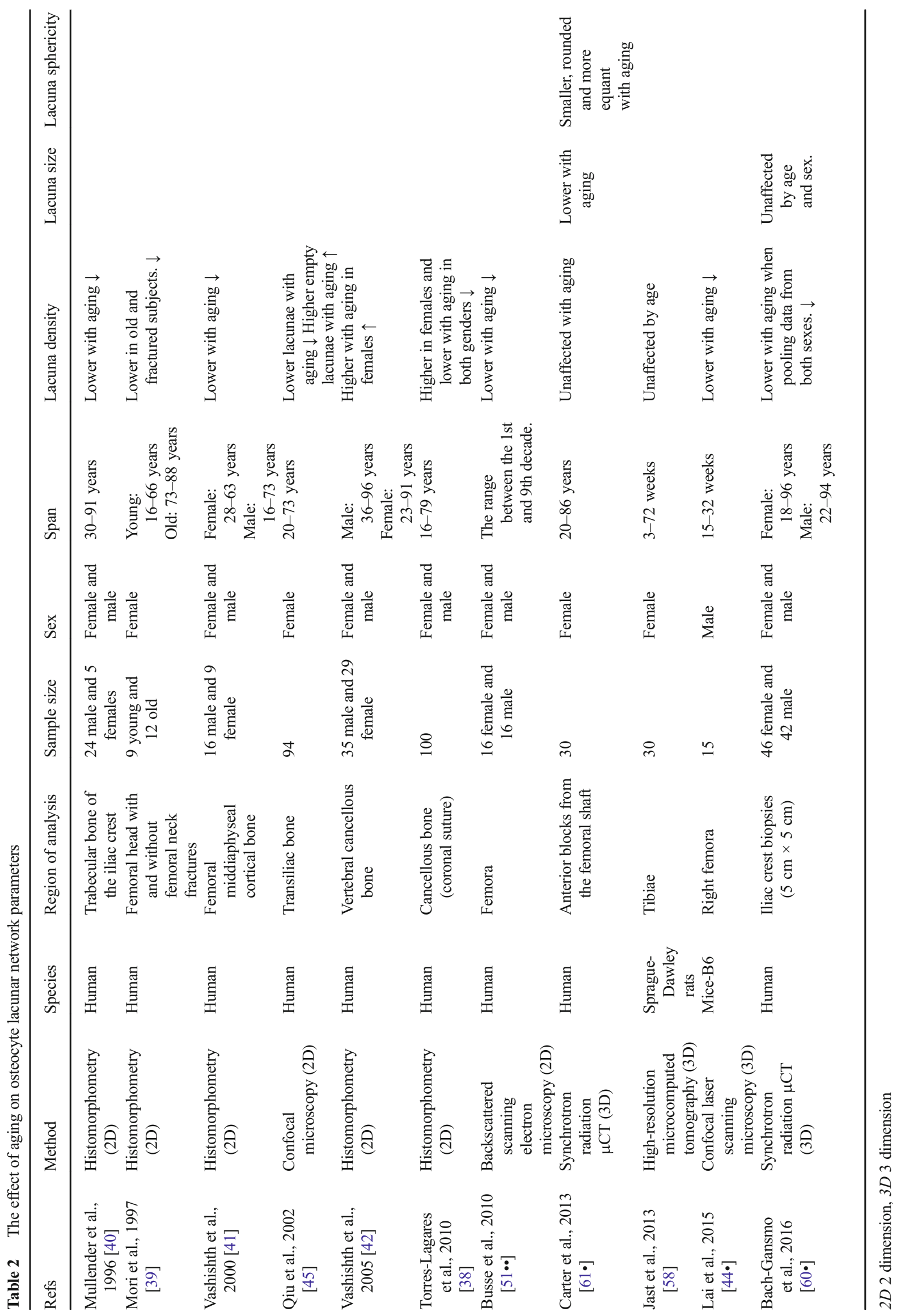


trabecular number, increased trabecular spacing, and unaffected or decreased trabecular thickness $[89,90]$. In the cortical bone, aging causes endocortical resorption and formation on the periosteal surface, leading to cortical thinning and marrow cavity expansion.

The mechanical quality of the bone does not only depend on bone geometry at the macrolevel [91-95], but also on microporosities (including the LCN) [96, 97••, 98, 99]. More specifically, changes in the volume of the LCN due to osteocytic osteolysis have been shown to affect the local mechanical properties of the bone $[87 \cdot, 100 \bullet \cdot]$. In mice, alteration in the volume of the LCN during lactation reduced the elastic modulus of the bone tissue by $13 \%$. These changes were only temporary as the elastic modulus returned to normal levels by 1 week postlactation $[100 \bullet \cdot]$.

Alterations in the lacuna density likely play an important role in mechanical failure behavior of the bone. First, the LCN has been hypothesized to have a direct effect on bone fracture behavior either by acting as local stress concentrators that cause crack initiation $[8,31]$, or by dissipating energy and acting as barriers to slow down the propagation of microcracks [101]. Second, it has been suggested that a sufficient number of osteocytes is necessary for a proper bone repair [97••]. Reduced osteocyte density due to osteocyte apoptosis and the

\section{Young}

\begin{tabular}{ccc} 
Macro-level & Micro-level & Nano-level \\
\hline$\overline{1 \mathrm{~mm}}$ & $\overline{0.5 \mathrm{~mm}}$ & $\overline{10 \mu \mathrm{m}}$
\end{tabular}

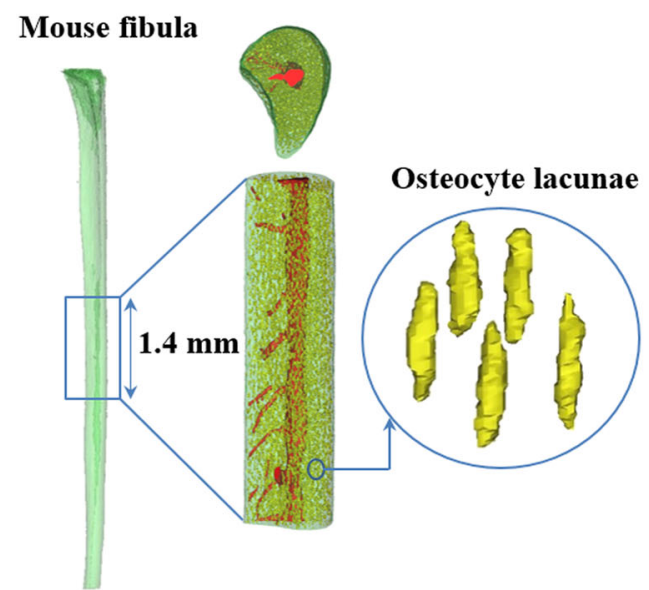

a

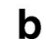

Fig. 1 Aging alters bone structure at the macrolevel, microlevel, and nanolevel. Medullary area, mean periosteal perimeter, and mean endosteal perimeter are significantly larger for old mice compared with young ones. With advancing age, vascular canal density reduces. Furthermore, osteocyte lacunae become smaller and more spherical with increasing age. (A) 3D-rendering of a whole C57BL/6 female mouse fibula at young age (5-months) using microcomputed tomography $(\mu \mathrm{CT})$ scans at $5-\mu \mathrm{m}$ resolution. (B) 3D-rendering of accumulation of mineral in lacunae with aging causes disturbs the bone remodeling process. More specifically, mineralized lacunae lead to decreased energy absorbing and dissipating capacities of the bone [102], and may cause the bone to become more brittle and susceptible to fragile fracture. A reduction in osteocyte number density can cause disturbance of canalicular fluid flow and decreased microdamage detection, resulting in impaired bone repair and decreased bone resistance to fracture [97••, 103-105]. In addition, the reduction in canalicular number could result in poor connectivity between osteocytes, and a hampered nutrition to osteocytes which can affect osteocyte mechanosensivity and ultimately bone quality and fracture resistance $[106 \bullet \bullet$.

With aging, conflicting results on changes in osteocyte lacunar number density (lacuna number per bone volume or bone area) have been reported (Table 2). A reduction in osteocyte lacunar number density with aging has been reported in the human cancellous bone [38-41, 45, 51••], human iliac crest cortical bone [60॰], and murine femoral cortical bone [44•]. This reduction could result from osteocyte apoptosis and subsequent mineralization of the lacunar space, called micropetrosis $[51 \bullet \cdot, 107]$. In contrast, an increase in the osteocyte lacunar density with age has been found in the female vertebral cancellous bone [42], whereas no dependency on

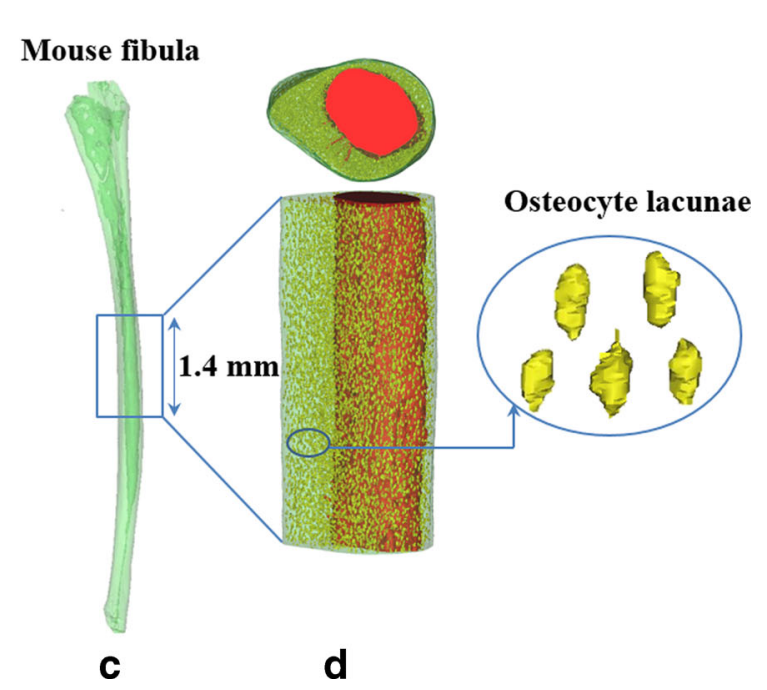

osteocyte lacunae and vascular canal network together with medullary cavity at midfibula diaphysis at young age using $\mu \mathrm{CT}$ scans at $0.70-\mu \mathrm{m}$ resolution. (C) 3D-rendering of a whole C57BL/6 female mouse fibula at old age (23-months) using $\mu \mathrm{CT}$ scans at $5-\mu \mathrm{m}$ resolution. (D) $3 \mathrm{D}$ rendering of osteocyte lacunae and the vascular canal network together with medullary cavity at midfibula diaphysis at old age using $\mu \mathrm{CT}$ scans at $0.70-\mu \mathrm{m}$ resolution 
age was detected in the cortical bone from the femora of women [61•], and in rat tibia [58]. These discrepancies might be attributed to the species investigated, sex, the different span of aging, sample size, tissue type, as well as to differences in analytical techniques used.

In addition to osteocyte density, also osteocyte shape could affect bone mechanical behavior. As mentioned before, osteocyte lacunae have been hypothesized to be capable of amplifying local tissue strains around the osteocyte cell bodies. Hence, alterations in lacunar shape could affect the transition of strains to the direct osteocyte microenvironment [8]. The osteocytes will then experience a locally modified mechanical environment resulting in an adaptive response to mechanical loading $[4 \cdot \bullet, 108]$. With aging, changes in the morphology of osteocyte lacunae have been reported but again with conflicting data. Whereas the lacunae became smaller and more spherical in the human femora [61•], and in the fibula of C57BL/6 mice [109] (Fig. 1), no significant changes in lacuna volume were observed in the human iliac crest bone [60•], nor in the femora of C57BL/6 mice [44•]. Small lacunae with higher sphericity in the aged bones could result from ongoing mineralization of the lacunar space before complete micropetrosis occurs due to aging $[61 \bullet, 107]$. The lacunar shape changes are possibly reflected in changes in osteocyte shape, since the same morphology and alignment of osteocytes and their lacunae have been shown in situ using confocal laser scanning microscopy and nano-computed tomography $[9 \bullet, 10 \bullet]$. If osteocyte cell shape indeed changes with aging, this could relate to changes in mechanosensitivity. Osteocyte shape is dependent on cytoskeletal architecture [110, 111], which plays a key role in the osteocyte response to mechanical loading. Interestingly, round osteocytes are more mechanosensitive and require less mechanical force than flat ones in order to release nitric oxide, even though they are more compliant compared to flat osteocyte cells [11••]. Thus, based on this evidence, one can hypothesize that with aging, smaller and more spherical lacunae are related to smaller and more spherical osteocytes, which could be related to an altered capability to respond to mechanical loads leading to a change in the maintenance of bone mass and architecture.

A final aspect of the LCN to consider is the canaliculi. With aging, no dependence on age in canalicular number density was found in the cortical bone from the femora of women [44•]. On the other hand, a reduced number of canaliculi per lacuna has been found [106••, 43], and these were found to be smaller [52]. Theoretical considerations predict that a smaller amount of canaliculi per lacuna would give rise to lower strain levels around the osteocytes, leading to a reduced mechanosensitivity response of the osteocytes [31].

\section{Conclusion}

In conclusion, aging is associated with changes in osteocyte lacuno-canalicular network (LCN) with respect to the shape and number density. Though extensive quantitative data is lacking, evidence exists that the osteocyte lacunae are becoming smaller and more spherical with aging. Additionally, in spite of conflicting results on age-related changes in osteocyte lacunar and canalicular number density, mostly, a reduction with aging has been reported. Since osteocytes can sense matrix strain directly via their cell bodies and the magnitude of the osteocyte signal is likely related to the number of osteocytes and their canaliculi contributing to the signal, the variations in osteocyte morphology and osteocyte number density may cause changes in mechanotransduction. This could be related to an altered capability to respond to mechanical loads leading to a change in the maintenance of bone mass and architecture with aging. Yet, whether the shape of the osteocyte lacuna can affect the bone mechanobiological response still needs confirmation. Considering the crucial role of osteocyte to maintain a healthy bone, a better understanding of the way osteocyte shape is related to its capability to direct bone formation and resorption may help to unravel whether changes in osteocytes and the LCN are related to the reduced bone adaptive response as seen with aging.

Acknowledgements This work was funded by the European Commission through MOVE-AGE, an Erasmus Mundus Joint Doctorate programme (2011-0015).

\section{Compliance with Ethical Standards}

Conflict of Interest Astrid Bakker, Hanyeh Hemmatian, Gerrit van Lenthe, and Jenneke Klein-Nulend declare no conflict of interest.

Human and Animal Rights and Informed Consent All reported studies/experiments with human or animal subjects performed by the authors have been previously published and complied with all applicable ethical standards (including the Helsinki Declaration and its amendments, institutional/national research committee standards, and international/national/institutional guidelines).

Open Access This article is distributed under the terms of the Creative Commons Attribution 4.0 International License (http:// creativecommons.org/licenses/by/4.0/), which permits unrestricted use, distribution, and reproduction in any medium, provided you give appropriate credit to the original author(s) and the source, provide a link to the Creative Commons license, and indicate if changes were made. 


\section{References}

Papers of particular interest, published recently, have been highlighted as:

- Of importance,

- Of major importance

1.• Klein-nulend J, Van Oers RFM, Bakker AD, Bacabac RG. Bone cell mechanosensitivity, estrogen deficiency, and osteoporosis. J Biomech. 2015;48(5):855-65. https://doi.org/10.1016/j.jbiomech. 2014.12.007. This review highlighted current insights on how osteocytes sense mechanical loading placed on whole bones with emphasizing on the role of estrogen in signaling pathway activation by mechanical loads

2. Hernlund E, Svedbom A, Ivergård M, Compston J, Cooper C, Stenmark J, et al. Osteoporosis in the European Union: medical management, epidemiology and economic burden: a report prepared in collaboration with the International Osteoporosis Foundation (IOF) and the European Federation of Pharmaceutical Industry Associations (EFPIA). Arch Osteoporos. 2013;8:136. https://doi. org/10.1007/s11657-013-0136-1.

3. Wolff J. Das Gesetz der Transform der Knochen. Berlin: Hirschwald; 1892.

4.• Klein-Nulend J, Bakker AD, Bacabac RG, Vatsa A, Weinbaum S. Mechanosensation and transduction in osteocytes. Bone. 2013;54(2):182-90. https://doi.org/10.1016/j.bone.2012.10.013. This review emphasized the role of osteocytes play in bone adaptation process. It also focused on how the cells could be activated by mechanical sitimuli, how the cells percive the loading, and how they respod and ultimately direct the mechanical bone adaptation

5.• Klein-Nulend J, Bacabac RG, Bakker AD. Mechanical loading and how it affects bone cells: the role of the osteocyte cytoskeleton in maintaining our skeleton. Eur Cell Mater. 2012;24:278-91. This review focused on bone mass adaptation to mechanical loads and on how osteocytes sense mechanical loads placed on whole bones. Particularly, it is emphazied on the role of the cytoskeleton of the osteocyte in mechanosensing

6. Bakker AD, Klein-Nulend J, Tanck E, Heyligers IC, Albers GH, Lips $\mathrm{P}$, et al. Different responsiveness to mechanical stress of bone cells from osteoporotic versus osteoarthritic donors. Osteoporos Int. 2006;17(6):827-33. https://doi.org/10.1007/s00198-006-0072-7.

7. Sterck JG, Klein-Nulend J, Lips P, Burger EH. Response of normal and osteoporotic human bone cells to mechanical stress in vitro. Am J Phys. 1998;274(6 Pt 1):E1113-20.

8. Nicolellaa DP, Moravits DE, Galea AM, Bonewald LF, Lankford JL. Osteocyte lacunae tissue strain in cortical bone. J Biomech. 2006;39(9): 1735-43. https://doi.org/10.1016/j.jbiomech.2005.04.032.

9. van Hove RP, Nolte PA, Vatsa A, Semeins CM, Salmon PL, Smit $\mathrm{TH}$, et al. Osteocyte morphology in human tibiae of different bone pathologies with different bone mineral density - is there a role for mechanosensing? Bone. 2009;45(2):321-9. https://doi.org/10. 1016/j.bone.2009.04.238. This study reported that the shape of osteocytes and their lacunae are significantly different in the tibia of individuals with osteoporosis, osteopenia, and osteoarthritis with different bone mineral density, which can cause differences in the matrix strain around the osteocytes

10. Vatsa A, Breuls RG, Semeins CM, Salmon PL, Smit TH, KleinNulend J. Osteocyte morphology in fibula and calvaria - is there a role for mechanosensing? Bone. 2008;43(3):452-8. https://doi. org/10.1016/j.bone.2008.01.030. This study found more flattened and elongated osteocytes and lacunae in fibula loaded unidirectionally than in calvarial bone, which is loaded in different directions
11.• Bacabac RG, Mizuno D, Schmidt CF, MacKintosh FC, Van Loon JJW, Klein-Nulend J, et al. Round versus flat: bone cell morphology, elasticity, and mechanosensing. J Biomech. 2008;41(7): 1590-8. https://doi.org/10.1016/j.jbiomech.2008.01.031. This study showed that the round osteocytes are more mechanosensitive and required less mechanical force than flat ones in order to respond

12. Robling AG, Niziolek PJ, Baldridge LA, Condon KW, Allen MR, Alam I, et al. Mechanical stimulation of bone in vivo reduces osteocyte expression of Sost/sclerostin. J Biol Chem. 2008;283(9):5866-75. https://doi.org/10.1074/jbc.M705092200.

13. You L, Temiyasathit S, Lee P, Kim CH, Tummala P, Yao W, et al. Osteocytes as mechanosensors in the inhibition of bone resorption due to mechanical loading. Bone. 2008;42(1):172-9. https://doi. org/10.1016/j.bone.2007.09.047.

14. Santos A, Bakker AD, Zandieh-Doulabi B, Semeins CM, KleinNulend J. Pulsating fluid flow modulates gene expression of proteins involved in Wnt signaling pathways in osteocytes. J Orthop Res. 2009;27(10):1280-7. https://doi.org/10.1002/jor.20888.

15. el Haj AJ, Minter SL, Rawlinson SC, Suswillo R, Lanyon LE. Cellular responses to mechanical loading in vitro. J Bone Miner Res. 1990;5(9):923-32. https://doi.org/10.1002/jbmr.5650050905.

16. Lee K, Jessop H, Suswillo R, Zaman G, Lanyon L. Endocrinology: bone adaptation requires oestrogen receptor-alpha. Nature. 2003;424(6947):389. https://doi.org/10.1038/424389a.

17. Terai K, Takano-Yamamoto T, Ohba Y, Hiura K, Sugimoto M, Sato M, et al. Role of osteopontin in bone remodeling caused by mechanical stress. J Bone Miner Res. 1999;14(6):839-49. https:// doi.org/10.1359/jbmr.1999.14.6.839.

18. Tatsumi S, Ishii K, Amizuka N, Li M, Kobayashi T, Kohno K, et al. Targeted ablation of osteocytes induces osteoporosis with defective mechanotransduction. Cell Metab. 2007;5(6):464-75. https://doi.org/10.1016/j.cmet.2007.05.001.

19. Kulkarni RN, Bakker AD, Everts V, Klein-Nulend J. Inhibition of osteoclastogenesis by mechanically loaded osteocytes: involvement of MEPE. Calcif Tissue Int. 2010;87(5):461-8. https://doi. org/10.1007/s00223-010-9407-7.

20. Nakashima T, Hayashi M, Fukunaga T, Kurata K, Oh-Hora M, Feng JQ, et al. Evidence for osteocyte regulation of bone homeostasis through RANKL expression. Nat Med. 2011;17(10):12314. https://doi.org/10.1038/nm.2452.

21. Xiong J, Onal M, Jilka RL, Weinstein RS, Manolagas SC, O'Brien CA. Matrix-embedded cells control osteoclast formation. Nat Med. 2011;17:1235-41. https://doi.org/10.1038/nm.2448.

22. Sugawara Y, Ando R, Kamioka H, Ishihara Y, Murshid SA, Hashimoto K, et al. The alteration of a mechanical property of bone cells during the process of changing from osteoblasts to osteocytes. Bone. 2008;43(1):19-24. https://doi.org/10.1016/j. bone.2008.02.020.

23. Litzenberger JB, Kim J-B, Tummala P, Jacobs CR. Beta1 integrins mediate mechanosensitive signaling pathways in osteocytes. Calcif Tissue Int. 2010;86(4):325-32. https://doi.org/10.1007/ s00223-010-9343-6.

24. Santos A, Bakker AD, Zandieh-Doulabi B, de Blieck-Hogervorst JMA, Klein-Nulend J. Early activation of the $\beta$-catenin pathway in osteocytes is mediated by nitric oxide, phosphatidyl inositol-3 kinase/Akt, and focal adhesion kinase. Biochem Biophys Res Commun. 2010;391(1):364-9. https://doi.org/10.1016/j.bbrc. 2009.11.064.

25. Price C, Zhou X, Li W, Wang L. Real-time measurement of solute transport within the lacunar-canalicular system of mechanically loaded bone: direct evidence for load-induced fluid flow. J Bone Miner Res. 2011;26(2):277-85. https://doi.org/10.1002/jbmr.211.

26. Fritton SP, Weinbaum S. Fluid and solute transport in bone: flowinduced mechanotransduction. Annu Rev Fluid Mech. 2009;41: 347-74. https://doi.org/10.1146/annurev.fluid.010908.165136. 
27. Bakker AD, Soejima K, Klein-Nulend J, Burger EH. The production of nitric oxide and prostaglandin $\mathrm{E}(2)$ by primary bone cells is shear stress dependent. J Biomech. 2001;34(5):671-7.

28. Klein-Nulend J, van der Plas A, Semeins CM, Ajubi NE, Frangos JA, Nijweide PJ, et al. Sensitivity of osteocytes to biomechanical stress in vitro. FASEB J. 1995;9(5):441-5.

29. Klein-Nulend J, Semeins CM, Ajubi NE, Nijweide PJ, Burger EH. Pulsating fluid flow increases nitric oxide (NO) synthesis by osteocytes but not periosteal fibroblasts - correlation with prostaglandin upregulation. Biochem Biophys Res Commun. 1995;217(2):640-8.

30. Liu C, Zhao Y, Cheung W-Y, Gandhi R, Wang L, You L. Effects of cyclic hydraulic pressure on osteocytes. Bone. 2010;46(5):144956. https://doi.org/10.1016/j.bone.2010.02.006.

31. Bonivtch AR, Bonewald LF, Nicolellaa DP. Tissue strain amplification at the osteocyte lacuna: a microstructural finite element analysis. J Biomech. 2007;40(10):2199-206. https://doi.org/10. 1016/j.jbiomech.2006.10.040.

32. Robinson JA, Chatterjee-Kishore M, Yaworsky PJ, Cullen DM, Zhao W, Li C, et al. Wnt/beta-catenin signaling is a normal physiological response to mechanical loading in bone. J Biol Chem. 2006;281(42):31720-8. https://doi.org/10.1074/jbc. M602308200.

33. Goggin PM, Zygalakis KC, Oreffo ROC, Schneider P. Highresolution 3D imaging of osteocytes and computational modelling in mechanobiology: insights on bone development, ageing, health and disease. Eur Cell Mater. 2016;31:264-95. This review emphasized the microstructural characteristics of the osteocyte network and lacuno-canalicular network (ON\&LCN) in health and disease and summarized the techniques used for visualization of ON\&LCN

34. Langer M, Peyrin F. 3D X-ray ultra-microscopy of bone tissue. Osteoporos Int. 2015:441-55. https://doi.org/10.1007/s00198015-3257-0.

35. Schneider P, Meier M, Wepf R, Müller R. Towards quantitative 3D imaging of the osteocyte lacuno-canalicular network. Bone. 2010;47(5):848-58. https://doi.org/10.1016/j.bone.2010.07.026.

36.• Webster DJ, Schneider P, Dallas SL, Müller R. Studying osteocytes within their environment. Bone. 2013;54(2):285-95. https:// doi.org/10.1016/j.bone.2013.01.004. This study reviewed both ex vivo and in vivo imaging techniques which are able to visualize and study osteocytes. Furthermore, live cell imaging methods as well as in vivo models and microfluidic imaging were also dicussed

37. Cardoso L, Fritton SP, Gailani G, Benalla M, Cowin SC. Advances in assessment of bone porosity, permeability and interstitial fluid flow. J Biomech. 2013;46(2):253-65. https://doi.org/ 10.1016/j.jbiomech.2012.10.025.

38. Torres-Lagares D, Tulasne JF, Pouget C, Llorens A, Saffar JL, Lesclous P. Structure and remodelling of the human parietal bone: an age and gender histomorphometric study. J CranioMaxillofacial Surg. 2010;38(5):325-30. https://doi.org/10.1016/j. jcms.2009.07.012.

39. Mori S, Harruff R, Ambrosius W, Burr DB. Trabecular bone volume and microdamage accumulation in the femoral heads of women with and without femoral neck fractures. Bone. 1997;21(6):521-6.

40. Mullender MG, van der Meer DD, Huiskes R, Lips P. Osteocyte density changes in aging and osteoporosis. Bone. $1996 \mathrm{Feb} ; 18(2)$ : 109-13.

41. Vashishth D, Verborgt O, Divine G, Schaffler MB, Fyhrie DP. Decline in osteocyte lacunar density in human cortical bone is associated with accumulation of microcracks with age. Bone. 2000;26(4):375-80. https://doi.org/10.1016/S8756-3282(00) 00236-2.

42. Vashishth D, Gibson GJ, Fyhrie DP. Sexual dimorphism and age dependence of osteocyte lacunar density for human vertebral cancellous bone. Anat Rec - Part A Discov Mol Cell Evol Biol. 2005;282(August 2004):157-62. https://doi.org/10.1002/ar.a.20146.

43. Hirose S, Li M, Kojima T, de Freitas PHL, Ubaidus S, Oda K, et al. A histological assessment on the distribution of the osteocytic lacunar canalicular system using silver staining. J Bone Miner Metab. 2007;25(6):374-82. https://doi.org/10.1007/ s00774-007-0764-X.

44. Lai X, Price C, Modla S, Thompson WR, Caplan J, Kirn-Safran $\mathrm{CB}$, et al. The dependences of osteocyte network on bone compartment, age, and disease. Bone Res. 2015;3(November 2014): 15009. https://doi.org/10.1038/boneres.2015.9. This study analyzed the morphometric parameters of lacunocanalicular network as a function of age and disease (perlecan deficiency and diabetes). Reductions in osteocyte lacunar number density with aging have been reported in murine femoral cortical bone, while no dependence on age in osteocyte canalicular number density as well as in the lacuna volume is detected in cortical bone from femora of black six mice.

45. Qiu S, Rao DS, Palnitkar S, Parfitt AM. Age and distance from the surface but not menopause reduce osteocyte density in human cancellous bone. Bone. 2002;31(2):313-8.

46. Kamioka H, Honjo T, Takano-Yamamoto T. A three-dimensional distribution of osteocyte processes revealed by the combination of confocal laser scanning microscopy and differential interference contrast microscopy. Bone. 2001;28(2):145-9.

47. Sugawara Y, Ando R, Kamioka H, Ishihara Y, Honjo T, Kawanabe $\mathrm{N}$, et al. The three-dimensional morphometry and cell-cell communication of the osteocyte network in chick and mouse embryonic calvaria. Calcif Tissue Int. 2011;88(5):416-24. https://doi. org/10.1007/s00223-011-9471-7.

48. Kamel-elsayed SA, Tiede-lewis L, Lu Y, Veno PA, Dallas SL. Novel approaches for two and three dimensional multiplexed imaging of osteocytes. Bone. 2015;76:129-40. https://doi.org/10. 1016/j.bone.2015.02.011.

49. Jones CW, Smolinski D, Keogh A, Kirk TB, Zheng MH. Confocal laser scanning microscopy in orthopaedic research. Prog Histochem Cytochem. 2005;40(1):1-71. https://doi.org/10.1016/ j.proghi.2005.02.001.

50. Sugawara Y, Kamioka H, Honjo T, Tezuka KI, Takano-Yamamoto T. Three-dimensional reconstruction of chick calvarial osteocytes and their cell processes using confocal microscopy. Bone. 2005;36(5):877-83. https://doi.org/10.1016/j.bone.2004.10.008.

51.• Busse B, Djonic D, Milovanovic P, Hahn M, Püschel K, Ritchie $\mathrm{RO}$, et al. Decrease in the osteocyte lacunar density accompanied by hypermineralized lacunar occlusion reveals failure and delay of remodeling in aged human bone. Aging Cell. 2010;9(6):1065-75. https://doi.org/10.1111/j.1474-9726.2010.00633.x. This study showed an age-related reduction in osteocyte lacunar number density causing deteriorations in the canalicular fluid flow and an age-related increase in hypermineralized lacuna which may cause bone brittle and fragile

52. Okada S, Yoshida S, Ashrafi SH, Schraufnagel DE. The canalicular structure of compact bone in the rat at different ages. Microsc Microanal. 2002;8:104-15. https://doi.org/10.1017/ S1431927601020037.

53. Kubek DJ, Gattone VH 2nd, Allen MR. Methodological assessment of acid-etching for visualizing the osteocyte lacunarcanalicular networks using scanning electron microscopy. Microsc Res Tech. 2010;73(3):182-6. https://doi.org/10.1002/ jemt.20772.

54. You L-D, Weinbaum S, Cowin SC, Schaffler MB. Ultrastructure of the osteocyte process and its pericellular matrix. Anat Rec A Discov Mol Cell Evol Biol. 2004;278(2):505-13. https://doi.org/ 10.1002/ar.a.20050.

55. McNamara LM, Majeska RJ, Weinbaum S, Friedrich V, Schaffler MB. Attachment of osteocyte cell processes to the bone matrix. 
Anat Rec (Hoboken). 2009;292(3):355-63. https://doi.org/10. 1002/ar.20869.

56. Rubin MA, Jasiuk I. The TEM characterization of the lamellar structure of osteoporotic human trabecular bone. Micron. 2005;36(7-8): 653-64. https://doi.org/10.1016/j.micron.2005.07.010.

57. Hemmatian H, Laurent MR, Ghazanfari S, Vanderschueren D, Bakker AD, Klein-Nulend J, et al. Accuracy and reproducibility of mouse cortical bone microporosity as quantified by desktop microcomputed tomography. PLoS ONE. 2017;12(8):e0182996. https://doi.org/10.1371/journal.pone.0182996.

58. Jast J, Jasiuk I. Age-related changes in the 3D hierarchical structure of rat tibia cortical bone characterized by high-resolution micro-CT. J Appl Physiol. 2013;114(7):923-33. https://doi.org/10. 1152/japplphysiol.00948.2011.

59. Palacio-Mancheno PE, Larriera AI, Doty SB, Cardoso L, Fritton SP. 3D assessment of cortical bone porosity and tissue mineral density using high-resolution $\mu \mathrm{CT}$ : effects of resolution and threshold method. J Bone Miner Res. 2014;29(1):142-50. https://doi.org/10.1002/jbmr.2012.

60. Bach-Gansmo FL, Brüel A, Jensen MV, Ebbesen EN, Birkedal H, Thomsen JS. Osteocyte lacunar properties and cortical microstructure in human iliac crest as a function of age and sex. Bone. 2016;91:11-9. https://doi.org/10.1016/j.bone.2016.07.003. In this study, the osteocyte lacunar volumes showed no dependence neither on age nor on sex. No sex-related changes were seen in osteocyte lacunar density, and there was only a significant reduction with age when pooling data from both sexes

61. Carter Y, Thomas CDL, Clement JG, Cooper DML. Femoral osteocyte lacunar density, volume and morphology in women across the lifespan. J Struct Biol. 2013;183(3):519-26. https://doi.org/10. 1016/j.jsb.2013.07.004. This study showed osteocyte lacunae become smaller and more spherical with increasing age in human femora

62. Schneider P, Stauber M, Voide R, Stampanoni M, Donahue LR, Müller R. Ultrastructural properties in cortical bone vary greatly in two inbred strains of mice as assessed by synchrotron light based micro- and nano-CT. J Bone Miner Res. 2007;22(10):1557-70. https://doi.org/10.1359/jbmr.070703.

63. Müller R. Hierarchical microimaging of bone structure and function. Nat Rev Rheumatol. 2009;5(7):373-81. https://doi.org/10. 1038/nrrheum.2009.107.

64. Carter Y, Thomas CDL, Clement JG, Peele AG, Hannah K, Cooper DML. Variation in osteocyte lacunar morphology and density in the human femur - a synchrotron radiation micro-CT study. Bone. 2013;52(1):126-32. https://doi.org/10.1016/j.bone. 2012.09.010.

65. Dong P, Haupert S, Hesse B, Langer M, Gouttenoire P-J, Bousson $\mathrm{V}$, et al. 3D osteocyte lacunar morphometric properties and distributions in human femoral cortical bone using synchrotron radiation micro-CT images. Bone. 2014;60:172-85. https://doi.org/10. 1016/j.bone.2013.12.008.

66. Bach-Gansmo FL, Weaver JC, Jensen MH, Leemreize H, Mader KS, Stampanoni M, et al. Osteocyte lacunar properties in rat cortical bone: differences between lamellar and central bone. J Struct Biol. 2015;191(1):59-67. https://doi.org/10.1016/j.jsb.2015.05.005.

67. Hannah KM, Thomas CDL, Clement JG, De Carlo F, Peele AG. Bimodal distribution of osteocyte lacunar size in the human femoral cortex as revealed by micro-CT. Bone. 2010;47(5):866-71. https://doi.org/10.1016/j.bone.2010.07.025.

68. Britz HM, Carter Y, Jokihaara J, Leppänen OV, Järvinen TLN, Belev G, et al. Prolonged unloading in growing rats reduces cortical osteocyte lacunar density and volume in the distal tibia. Bone. 2012;51(5):913-9. https://doi.org/10.1016/j.bone.2012.08.112.

69. Cooper DML, Turinsky AL, Sensen CW, Hallgrímsson B. Quantitative 3D analysis of the canal network in cortical bone by micro-computed tomography. Anat Rec B New Anat. 2003;274(1):169-79. https://doi.org/10.1002/ar.b.10024.

70. Cooper DML, Matyas JR, Katzenberg MA, Hallgrimsson B. Comparison of microcomputed tomographic and microradiographic measurements of cortical bone porosity. Calcif Tissue Int. 2004;74(5):437-47.https://doi.org/10.1007/s00223-003-0071-z.

71. McCreadie BR, Hollister SJ, Schaffler MB, Goldstein SA. Osteocyte lacuna size and shape in women with and without osteoporotic fracture. J Biomech. 2004;37(4):563-72. https://doi. org/10.1016/S0021-9290(03)00287-2.

72. Deligianni DD, Apostolopoulos CA. Multilevel finite element modeling for the prediction of local cellular deformation in bone. Biomech Model Mechanobiol. 2008;7(2):151-9. https://doi.org/ 10.1007/s10237-007-0082-1.

73. Anderson EJ, Kaliyamoorthy S, Iwan J, Alexander D, Knothe Tate ML. Nano-microscale models of periosteocytic flow show differences in stresses imparted to cell body and processes. Ann Biomed Eng. 2005;33(1):52-62.

74. Anderson EJ, Knothe Tate ML. Idealization of pericellular fluid space geometry and dimension results in a profound underprediction of nano-microscale stresses imparted by fluid drag on osteocytes. J Biomech. 2008;41(8):1736-46. https://doi. org/10.1016/j.jbiomech.2008.02.035.

75. Stern AR, Nicolella DP. Measurement and estimation of osteocyte mechanical strain. Bone. 2013;54(2):191-5. https://doi.org/10. 1016/j.bone.2013.01.037. This review examined and reviewed the techniques used for measuring bone metrix strains locally around osteocytes in vivo

76. Verbruggen SW, Vaughan TJ, McNamara LM. Fluid flow in the osteocyte mechanical environment: a fluid-structure interaction approach. Biomech Model Mechanobiol. 2014;13(1)85-97. https://doi.org/10.1007/s10237-013-0487-y.

77. Dierolf M, Menzel A, Thibault P, Schneider P, Kewish CM, Wepf $\mathrm{R}$, et al. Ptychographic X-ray computed tomography at the nanoscale. Nature. 2010;467(7314):436-9. https://doi.org/10.1038/ nature09419.

78. Schneider P, Meier M, Wepf R, Müller R. Serial FIB/SEM imaging for quantitative $3 \mathrm{D}$ assessment of the osteocyte lacunocanalicular network. Bone. 2011;49(2):304-11. https://doi.org/ 10.1016/j.bone.2011.04.005.

79. Schneider P, Ruffoni D, Larsson D, Chiapparini I, Müller R. Image-based finite element models for the investigation of osteocyte mechanotransduction. J Biomech. 2012;45(1):S436. https:// doi.org/10.1016/S0021-9290(12)70437-2.

80. Buenzli PR, Sims NA. Quantifying the osteocyte network in the human skeleton. Bone. 2015;75:144-50. https://doi.org/10.1016/ j.bone.2015.02.016.

81. Belanger LF. Osteocytic osteolysis. Calcif Tissue Res. 1969;4(1): $1-12$.

82. Qing H, Ardeshirpour L, Divieti Pajevic P, Dusevich V, Jähn K, Kato S, et al. Demonstration of osteocytic perilacunar/canalicular remodeling in mice during lactation. J Bone Miner Res. 2012;27(5):1018-29. https://doi.org/10.1002/jbmr.1567. This study showed that osteocytes can enlarge their lacuna volume by removing bone from their perilacunar bone matrix in a process called osteocytic osteolysis during lactation

83. Dallas SL, Prideaux M, Bonewald LF. The osteocyte: an endocrine cell ... and more. Endocr Rev. 2013;34(5):658-90. https:// doi.org/10.1210/er.2012-1026.

84. Tazawa K, Hoshi K, Kawamoto S, Tanaka M, Ejiri S, Ozawa H. Osteocytic osteolysis observed in rats to which parathyroid hormone was continuously administered. J Bone Miner Metab. 2004;22:524-9. https://doi.org/10.1007/s00774-004-0519-x.

85. Sugawara Y, Kamioka H, Ishihara Y, Fujisawa N, Kawanabe N, Yamashiro T. The early mouse 3D osteocyte network in the 
presence and absence of mechanical loading. Bone. 2013;52(1): 189-96. https://doi.org/10.1016/j.bone.2012.09.033.

86. Vatsa A, Semeins CM, Smit TH, Klein-Nulend J. Paxillin localisation in osteocytes - is it determined by the direction of loading? Biochem Biophys Res Commun. 2008;377(4):101924. https://doi.org/10.1016/j.bbrc.2007.12.174.

87. Milovanovic P, Zimmermann EA, Riedel C, vom Scheidt A, Herzog L, Krause M, et al. Multi-level characterization of human femoral cortices and their underlying osteocyte network reveal trends in quality of young, aged, osteoporotic and antiresorptivetreated bone. Biomaterials. 2015;45:46-55. https://doi.org/10. 1016/j.biomaterials.2014.12.024. In this study, the mineralized lacunae density and distribution in the human femoral cortical bone were quantified in aging, osteoporosis, and alendronate-treatment states. Furthermore, the composition of bone matrix and its mechanical properties were also analyzed for a better understanding on the osteocytes' contribution to bone health and quality

88. Seeman E. Age- and menopause-related bone loss compromise cortical and trabecular microstructure. J Gerontol A Biol Sci Med Sci. 2013;68(10):1218-25. https://doi.org/10.1093/gerona/glt071.

89. Majumdar S, Genant HK, Grampp S, Newitt DC, Truong VH, Lin $\mathrm{JC}$, et al. Correlation of trabecular bone structure with age, bone mineral density, and osteoporotic status: in vivo studies in the distal radius using high resolution magnetic resonance imaging. J Bone Miner Res. 1997;12(1):111-8. https://doi.org/10.1359/ jbmr.1997.12.1.111.

90. Ding M, Hvid I. Quantification of age-related changes in the structure model type and trabecular thickness of human tibial cancellous bone. Bone. 2000;26(3):291-5.

91. Currey JD. The effect of porosity and mineral content on the Young's modulus of elasticity of compact bone. J Biomech. 1988;21(2):131-9.

92. Hernandez CJ, Beaupré GS, Keller TS, Carter DR. The influence of bone volume fraction and ash fraction on bone strength and modulus. Bone. 2001;29(1):74-8.

93. McCalden RW, McGeough JA, Barker MB, Court-Brown CM. Age-related changes in the tensile properties of cortical bone. The relative importance of changes in porosity, mineralization, and microstructure. J Bone Joint Surg Am. 1993;75(8): 1193-205.

94. Dong XN, Guo XE. The dependence of transversely isotropic elasticity of human femoral cortical bone on porosity. J Biomech. 2004;37(8):1281-7. https://doi.org/10.1016/j. jbiomech.2003.12.011.

95. Currey J. Incompatible mechanical properties in compact bone. J Theor Biol. 2004;231(4):569-80. https://doi.org/10.1016/j.jtbi. 2004.07.013.

96. Schneider P, Voide R, Stampanoni M, Donahue LR, Müller R. The importance of the intracortical canal network for murine bone mechanics. Bone. 2013;53(1):120-8. https://doi.org/10.1016/j. bone.2012.11.024.

97.• Ma YL, Dai RC, Sheng ZF, Jin Y, Zhang YH, Fang LN, et al. Quantitative associations between osteocyte density and biomechanics, microcrack and microstructure in OVX rats vertebral trabeculae. J Biomech. 2008;41(6):1324-32. https://doi.org/10. 1016/j.jbiomech.2008.01.017. This study demonstrated a positive correlation between the density of osteocyte and the quality of bone. It showed the changes in the density of osteocyte lacuna would influence the crack length and the strength of bone
98. Hazenberg JG, Taylor D, Lee TC. The role of osteocytes and bone microstructure in preventing osteoporotic fractures. Osteoporos Int. 2007;18(1):1-8. https://doi.org/10.1007/s00198-006-0222-y.

99. Voide R, Schneider P, Stauber M, van Lenthe GH, Stampanoni M, Müller R. The importance of murine cortical bone microstructure for microcrack initiation and propagation. Bone. 2011;49(6): 1186-93. https://doi.org/10.1016/j.bone.2011.08.011.

100.• Kaya S, Basta-Pljakic J, Seref-Ferlengez Z, Majeska RJ, Cardoso $\mathrm{L}$, Bromage T, et al. Lactation induced changes in the volume of osteocyte lacunar-canalicular space alter mechanical properties in cortical bone tissue. J Bone Miner Res. 2016; https://doi.org/10. $1002 / \mathrm{jbmr} .3044$. This study reported that changes in the volume of lacunar-canalicular network due to osteocytic osteolysis can affect the local mechanical properties of bone. Alternation in lacunar-canalicular volume without any changes in the matrix mineral content during lactation in mice results in $13 \%$ reduction in elastic modules of bone tissue. It returned to normal level by 1 week postlactation

101. O'Brien FJ, Taylor D, Lee TC. Microcrack accumulation at different intervals during fatigue testing of compact bone. J Biomech. 2003;36(7):973-80. https://doi.org/10.1016/S0021-9290(03) 00066-6.

102. Klein-Nulend J, Bonewald FL. The osteocyte. In Principles of bone biology. 3rd ed. San Diego Acad Press. 2008;153-174.

103. Burger EH, Klein-Nulend J, Smit TH. Strain-derived canalicular fluid flow regulates osteoclast activity in a remodelling osteon-a proposal. J Biomech. 2003;36(10):1453-9.

104. O'Brien CA, Jia D, Plotkin LI, Bellido T, Powers CC, Stewart SA, et al. Glucocorticoids act directly on osteoblasts and osteocytes to induce their apoptosis and reduce bone formation and strength. Endocrinology. 2004;145(4):1835-41. https://doi.org/10.1210/ en.2003-0990.

105. Mullender MG, Tan SD, Vico L, Alexandre C, Klein-Nulend J. Differences in osteocyte density and bone histomorphometry between men and women and between healthy and osteoporotic subjects. Calcif Tissue Int. 2005;77(5):291-6. https://doi.org/10. 1007/s00223-005-0043-6.

106.• Milovanovic P, Zimmermann EA, Hahn M, Djonic D, Püschel K, Djuric M, et al. Osteocytic canalicular networks: morphological implications for altered mechanosensitivity. ACS Nano. 2013;7(9):7542-51. https://doi.org/10.1021/nn401360u. This study showed a reduction of $30 \%$ in the number of canaliculi per osteocyte lacuna in aged individuals

107. Frost HM. Micropetrosis. J Bone Joint Surg Am. 1960;42-A:144-50.

108. Burger EH, Klein-Nulend J. Mechanotransduction in bone-role of the lacuno-canalicular network. FASEB J. 1999;13(Suppl): S101-12.

109. Hemmatian H, Laurent M, Claessens F, Vanderschueren D, van Lenthe GH. Age-related changes in the 3D microstructural mouse cortical bone using high resolution desktop micro-CT system. Atlanta: 38th Annu Meet Am Soc Bone Miner Res (ASBMR); 2016. p. 16-9.

110. McGarry JG, Klein-Nulend J, Prendergast PJ. The effect of cytoskeletal disruption on pulsatile fluid flow-induced nitric oxide and prostaglandin E2 release in osteocytes and osteoblasts. Biochem Biophys Res Commun. 2005;330(1):341-8. https://doi.org/10. 1016/j.bbrc.2005.02.175.

111. Ajubi NE, Klein-Nulend J, Nijweide PJ, Vrijheid-Lammers T, Alblas MJ, Burger EH. Pulsating fluid flow increases prostaglandin production by cultured chicken osteocytes - a cytoskeletondependent process. Biochem Biophys Res Commun. 1996;225(1):62-8. https://doi.org/10.1006/bbrc.1996.1131. 